\title{
REGULAÇÃO, DOCILIZAÇÃO OU EMANCIPAÇÃO? \\ A PRODUTIVIDADE NA POLÍTICA EDUCACIONAL DA PÓS- \\ GRADUAÇÃO STRICTO SENSU BRASILEIRA
}

\author{
PIRES, Aparecida Carneiro (UFCG/CFP) \\ acppedagoga@yahoo.com.br \\ SILVA, Maria Cecília de Paula (UFBA/FACED) \\ cecilipaula@yahoo.com.br
}

\begin{abstract}
RESUMO
A presente pesquisa investigou os princípios de formação defendidos e definidos pela Pós-graduação stricto sensu em Educação a partir dos direcionamentos da Agência de Política de Avaliação e Financiamento (Capes) e critérios de produtividade, problematizando se estes atendem a princípios emancipatórios ou alienadores. A pesquisa histórica, de cunho qualitativo, contemplou a metodologia da investigação documental e oral, com vozes de pesquisadores/as comprometidos/as com esta temática, assim como documentos produzidos na literatura crítica. Para a análise dos dados, referendamo-nos em conceitos como intelectuais orgânicos, corpo, cultura, hegemonia e contra-hegemonia, apoiados em Gramsci, Marx e Engels e Silva, entre outros, numa perspectiva dialógica. A análise sobre a relação do corpo e a cultura na Pós-graduação stricto sensu apontou a compreensão de um corpo instrumental, em detrimento da formação do sujeito histórico emancipado, o que nos leva sugerir a necessidade de construção de elementos para uma contra-hegemonia, uma outra práxis educacional na formação dos sujeitos da pósgraduação brasileira.
\end{abstract}

Palavras-chave: Pós-graduação - Capes - produtividade - corpo e cultura - emancipação

\section{REGULATIZATION, TEACHABLENESS OR EMANCIPATION? THE PRODUCTIVITY IN EDUCATIONAL POLICY OF THE BRAZILIAN STRICTO SENSU POST GRADUASTE STUDIES}

\begin{abstract}
The presente search investigated the principles of training defended and determined by stricto sensu postgraduate studies in education from instructions of Agência de Política de Avaliação e Financiamento - Capes (Agency of Evaluation and Finance Policies) and criteria of productivity, discussing whether such criteria of productivity are accordance with alienated or emancipated principles. The historical search of qualitative matrix took into consideration the method of oral and documentary search, listening to researchers concerned with this affair, like documents written in critical literature. To analyze data, we have had references in concepts as the organic intellectual, body, culture, hegemony, counter-hegemony, based in Gramsci, Marx and Engels, and Silva, among others, in an outlook based in dialogue practice.
\end{abstract}


The analysis on body and culture in stricto sensu post graduate studies to the detriment of formation of the freed historical subject, what leads us to suggest the necessity of the construction of elements for a counter-hegemony, another education praxis in training of subjects of the Brazilian postgraduate studies.

Keywords: Postgraduate studies, Capes, productivity, body and culture, emancipation

\section{INTRODUÇÃO}

A pesquisa buscou investigar os princípios de formação que estão sendo definidos pela Pós-graduação stricto sensu em Educação, a partir dos direcionamentos da política de avaliação e financiamento da Coordenação de Aperfeiçoamento de Pessoal de Nível Superior (Capes), em seu percurso histórico. Buscou-se especificamente, contextualizar o papel da Pós-graduação em Educação diante das reconfigurações socioeconômicas, políticas e culturais do capitalismo; compreender a relação entre critérios de avaliação da Capes e a lógica de produtividade na Pós-Graduação stricto sensu em Educação; analisar documentos da Capes para este nível de ensino na área de Ciências Humanas e Educação; e entrevistar pesquisadores/as envolvidos/as nessa história em suas trajetórias acadêmicas, como Osmar Fávero, Vera Maria Candau, José Silvério Baía Horta e Marli André; a relação entre o dito e feito, entre as propostas oferecidas e sua materialização.

Bianchetti (2009) denomina a pós-graduação brasileira stricto sensu, no tempo presente, de a "era da produtividade", por esta impor aos/as pesquisadores/as uma lógica desumana de produção científica, a qual merece reflexões e posições críticas, tais como: para que e para quem queremos e devemos produzir?; em que sentido a lógica das políticas públicas empreendidas na Pós-graduação stricto sensu tem contribuído para o desenvolvimento do corpo e cultura dos envolvidos/as - professores/as e pósgraduandos/as? Os critérios estabelecidos pela Capes anunciam uma formação para a emancipação ${ }^{1}$ ou para alienação? Nesse artigo, trataremos de forma mais precisa dessas

\footnotetext{
1 "Emancipação" no dicionário do pensamento marxista, Bottomore (2012) está compreendida na perspectiva liberal clássica, a liberdade como ausência de interferência ou, ainda mais especificamente, de coerção. Isto é, ser (sou) livre para fazer aquilo que os outros não (me) impedem de fazer. Nesse sentido, é que Marx e os marxistas tendem a ver a liberdade em termos da eliminação dos obstáculos à emancipação humana, ou seja, ao múltiplo desenvolvimento das possibilidades humanas e à criação de uma forma de associação digna da condição humana.
} 
questões.

No que diz respeito à metodologia, a pesquisa utilizou revisão bibliográfica sobre a temática, contemplando fontes documentais e orais, utilizando-se conceitos como corpo, cultura, hegemonia e contra-hegemonia. Utilizamos entrevistas semiestruturadas, realizadas pessoalmente, mas também via Skype e por e-mail, aos/às professores/as que diretamente têm contribuído na formulação de políticas, pautadas em uma lógica diferenciada da realizada pela Capes e da perspectiva crítica que vem sendo construída durante o período e referenciada pelos grupos de trabalho da Associação Nacional de Pós-Graduação e Pesquisa em Educação (ANPEd). As entrevistas foram revistas pelos entrevistados/as e, dessa maneira, autorizadas.

Os dados e informações foram analisados a partir da expressão emancipação humana, presentes nas obras de Marx e Engels. Optamos por compreender o conteúdo dos documentos e das falas dos depoentes à luz de uma análise histórica, materialista e dialética, em que não existem pontos absolutos de partida, problemas resolvidos definitivamente, e nem avanços lineares, pois, toda verdade parcial só assume sua significação verdadeira no conjunto.

Para tal, fez-se necessário considerarmos o contexto histórico do objeto estudado, o que foi feito por meio de Políticas Educacionais da Pós-graduação stricto sensu, orientadas pela Capes, no tempo presente; leitura e interpretação dos documentos, com registros das contradições dessas políticas, e propostas alternativas de pesquisadores/as da área, como Fávero (1998), Gatti (2013), André (2013), Candau (2012), Horta (2009) e Cury (2009), dentre outros.

O diálogo com estes/as pesquisadores/as possibilitou-nos compreender que os desafios apresentados no contexto da Educação Superior, principalmente para a Pósgraduação stricto sensu, são oriundos de alterações significativas ocorridas com a ressignificação do papel do Estado Brasileiro frente ao projeto neoliberal instaurado em nosso país. Alterações, estas, que visam inserir formas de controle e de disciplina aos sujeitos, submetendo-os a uma intensa onda de produtividade, com intensificação das produções acadêmicas a um quantum inesgotável - um corpo produtivo com viés de alto rendimento como se fossem máquinas. 
Silva (2009), afirma que o "nosso" corpo segue sendo explorado a serviço do capital com tal maestria que, muitas vezes, sequer conseguimos perceber o grau de aviltamento a que chegamos, uma vez que a mais-valia absoluta continua desde os tempos da escravidão clássica e da servidão humana. $\mathrm{O}$ desenvolvimento acelerado das forças produtivas cria tecnologias impondo ao trabalhador um ritmo desenfreado de trabalho, tornando este sujeito num corpo produtivo, docilizado, regulado, e, "[...] através do conhecimento das possibilidades corporais são elaboradas formas de controle que permitem aumentar a produtividade, aumentar os recursos, melhorar as técnicas, enfim, formas disciplinares de domínio da vida." (SILVA, 2009, p. 53).

Com um mecanismo de intensificação e controle da produção do conhecimento, a Capes estabelece metas de publicações e organiza o sistema de pós-graduação a partir do número delas, em uma hierarquia realizada por critérios em que se julga os melhores. O sistema de fomento e avaliação da Capes tem se aperfeiçoado continuamente, objetivando consolidar a qualificação dos quadros para o Ensino Superior e pesquisa e possibilitando um padrão de excelência acadêmica aos programas de mestrado e doutorado.

Nessas condições, um programa é considerado de "excelência" se a maior parte do corpo de professores publica artigos em revistas que fazem parte de uma lista, denominada Qualis Capes, classificadas no espectro que varia de A1 a B2. A "produção científica" mede-se pelo número de artigos publicados em revistas nacionais e "internacionais".

Todavia, esta forma de avaliar tem recebido algumas críticas da comunidade acadêmica que questiona os critérios e mecanismos adotados, uma vez que estas avaliações têm se enveredado para a valorização de uma produtividade sob o ponto de vista quantitativo em detrimento do qualitativo. Trata-se exclusivamente, para os/as referidos/as autores/as, de uma dose consistente de colonialismo intelectual, um subproduto necessário do sistema de dominação de um país dependente em que aqueles que publicam mais, e por este motivo são considerados mais aptos cientificamente, estão no comando das ações.

De acordo com Fávero (1998) a avaliação da agência Capes é bastante discutida 
desde sua implantação a partir de 1976-77 e, em meados dos anos 80, passou a ser objeto de proposta alternativa da ANPed. Mas, apesar de revista e aperfeiçoada, ao longo desses anos, particularmente no início dos anos 90, a sistemática de avaliação da Capes tem gerado mais polêmicas.

O modelo adotado é proposto como exemplar para a avaliação das universidades, e os aperfeiçoamentos introduzidos nesses anos não atingiram os princípios, nem superaram questões fundamentais. No intuito de ilustrar a afirmação de Fávero, apresentaremos pressupostos, no âmbito da Educação, partindo das análises do texto: "ANPEd, A avaliação da pós-graduação em debate":

[...] o modelo da avaliação é reconhecidamente homogeneizador e tende a uma padronização dos Programas, caminhando, portanto, na direção oposta das discussões e análises que buscam contemplar sua rica diversidade. Várias alternativas ajudariam a flexibilizar a sistemática de avaliação, enfatizando seu caráter diagnóstico, com vista a respeitar as especificidades das áreas e Programas; levar em conta seu impacto local, regional, nacional e internacional. Urge, portanto, reverter a lógica classificatória, e instituir uma lógica que contemple principalmente: o diagnóstico, acompanhamento e incremento dos Programas, segundo a sua relevância regional e as condições em que atuam; A este respeito a área de Educação tem produção significativa que pode ser disponibilizada para o refinamento e a adequação do modelo de avaliação. Rio de Janeiro, 22 de julho de 2004. (V Plano Nacional de PósGraduação: subsídios apresentados pela ANPEd, 2004).

No documento "Síntese Preliminar de 2005-2010/Capes/PNPG", a comissão responsável pela elaboração do PNPG 2005-2010 adotou, como fase inicial dos trabalhos, uma ampla consulta aos interlocutores qualificados da comunidade científica e acadêmica. Encontramos referências ao II PNPG (1982-1985), frisando que o objetivo central continua a ser a formação de recursos humanos, qualificados para as atividades docentes, mesmo apresentando alguns desafios:

Pode-se então concluir que nesse plano, a questão central não é apenas a expansão da capacitação docente, mas a elevação de sua qualidade, enfatizando-se, nesse processo, a importância da avaliação, da participação da comunidade científica e do desenvolvimento da pesquisa científica e tecnológica. (CAPES, 2005, p. 4).

Ainda que de maneira abreviada, estes dados demonstram que a capacitação de 
docentes, tanto na educação básica quanto na superior, continua sendo um desafio central para a pós-graduação brasileira. Nessa mesma direção, Fávero, Horta e Almeida, no documento "Comentários críticos sobre os $1^{\circ} P N P G$ e $1^{\circ} P N P G E$ ", versão preliminar (FGV/SESAE, junho 1978), apontaram subsídios centrais à elaboração dos $2^{\circ}$ PNPG e $2^{\circ}$ PNPGE:

[...] nota-se que passa a ser imperativo ou normativo a partir da apresentação de "sugestões" que incluem mecanismos de controle e avaliação... O uso abusivo do verbo "dever" é outro indicador da natureza do Plano; Do ponto de vista metodológico não há qualquer indicação de que o Plano tenha-se fundamentado em um diagnóstico ou no levantamento de necessidades. Vale ainda mencionar o fato de que a baixa produtividade dos cursos (número de teses defendidas ou de alunos titulados), bem como a qualidade dos programas (incidências de áreas, distribuição de docentes em termos de titulação) foram avaliadas, segundo se pode inferir, por critérios apenas quantitativos, quando em educação desejável seria a inclusão também dos aspectos qualitativos; [...] ambos elaborados de um ponto de vista apenas tecnocrata, exemplo típico do poder dirigindo o saber. (grifos nossos).

A partir de leituras realizadas no sítio da Capes é possível destacar duas observações: a) estreita relação da avaliação e fomento em que as universidades com melhores conceitos são premiadas; b) ênfase no "produtivismo" acadêmico, que em função do quantitativo das produções, tem suplantado o qualitativo. Os programas das universidades, com conceitos considerados excelentes pela Capes, obtêm um número maior de bolsas e, aqueles com menor nota, recebem como punição, um número menor de bolsas, risco do descredenciamento do programa, uma vez que prevalecem à centralização do sistema de avaliação, principalmente ações políticas desenvolvidas pela referida instituição. Encontramos em C. M. Castro (1985), no artigo "Há produção científica no Brasil?”, orientações e determinações para que a política educacional da pós-graduação stricto sensu brasileira seja pautada nestes aspectos:

Vemos, portanto, que a ciência é muito polarizada pelos países hegemônicos. Esse dilema nacional versus internacional é verdadeiro e não pode ser minimizado: Peão de uma ciência sofisticada ou rei de um arremedo tupiniquim de ciência? Se para Camões o português era o túmulo da literatura, não será menos verdade que o português será o túmulo da ciência brasileira? (p. 43). 
Lucídio Bianchetti (2008) analisou a relação das políticas educacionais para a pós-graduação stricto sensu, com a lógica do mercado, questionando no processo avaliativo: estratégias utilizadas; perspectiva predominantemente quantitativa $\mathrm{e}$ verticalizada do órgão avaliador; critérios padronizados para realidades muito diversas, seja no interior de uma área, seja na relação entre áreas, com perfis epistemológicos tão diferentes e situação geográfica tão diversa. Frisou, como principais problemas, a avaliação com critérios homogêneos, abrangendo áreas heterogêneas; predomínio de uma perspectiva contábil, priorizando os resultados em detrimento de processos; preocupação com rankings, por considerar que este sistema induz ao produtivismo.

$\mathrm{O}$ referido autor traz à tona a discussão acerca da forma como se desenvolve atualmente a política de avaliação pelo viés dos professores submetidos à mesma. Para este, existe uma fórmula engenhosa nesse processo, que passa a exercer uma vinculação de "indução voluntária", qual seja: a vinculação do fomento à avaliação, dados significativos para que tanto o conceito de avaliação quanto o da educação sejam descaracterizados. Resultados que demonstram algumas consequências da proposta da avaliação Capes.

Neste mesmo sentido, Cury (2009) alerta-nos através de uma importante indagação: Como conseguir uma eficiência dos Programas de tal modo que suas bases sejam arranjos sob o signo de uma avaliação crítica, mensurável e qualitativa, sem ser submissa, nem à busca de um sucesso próprio do mercado competitivo, nem a uma versão corporativa que não reconheça a necessidade de avaliação crítica, séria e compromissada, pautada numa educação como bem público e não como serviço privado?

Ao nos determos aos paradoxos encontrados na materialização das políticas educacionais utilizadas pela Capes, outros elementos denotam a necessidade de melhoria das ações por esta instituição.

[...] isso é avassalador, não é mais docilidade de corpo, é docilidade de mente; está formando uma geração instrumentalmente. Mercadológico no sentido grande, não para atender o mercado, mas para essa produtividade de eficiência, essas matrizes que estão gerando esse tipo de avaliação, essas 
coisas. Essa loucura de você fazer, não pelo valor do artigo, mas pelo número de citações que ele recebe, sabe que isso é fajuto. (Informação verbal) ${ }^{2}$.

[...] progressivamente foi estabelecendo com muita força mecanismos de controle da pós-graduação. Nos últimos anos sua atuação tem enfatizado a avaliação e o controle, o que tem favorecido, na minha opinião, o engessamento da pós-graduação: modelo único, indicadores quantitativos, falta de sensibilidade para as diferenças regionais e vocações específicas dos programas, pressão de produtividade numérica, etc. (Informação verbal) ${ }^{3}$.

A afirmação acerca do descrédito com os planos nacionais de pós-graduação está explícita no documento elaborado pelo próprio autor em $1980^{4}$, "Das dificuldades de colaborar na elaboração de um Plano Nacional de Pós-Graduação":

\begin{abstract}
Qualquer discussão sobre os planos no Brasil - e os de Pós-Graduação são um bom exemplo: existem planos demais! Pode-se até afirmar que não se faz planejamento; elaboram-se planos; Em lugar de um processo comprometido e fecundo, resultante do conhecimento e da reflexão sobre a realidade e da decisão de nela intervir, através de mecanismos definidos por uma racionalidade técnica e escudados numa racionalidade política, tem-se uma sequência de documentos que, na maioria das vezes, se superpõem à realidade, quando não a ignoram. Uma segunda barreira é representada pela quase total ausência de avaliação dos "planos" [...] Aí está a causa última da inviabilidade dos planos: as diretrizes são ideias, não normas; as estratégias são sugestões, não caminhos. As racionalidades técnica e política não confluem e se complementam; nem mesmo se chocam: caminham paralelas. (FÁVERO, 1998).
\end{abstract}

Horta (2009) reitera que, o Comitê Avaliador precisa compreender mais as condições e o contexto de cada Programa, pois os Programas estão em contextos socioculturais diferentes. O padrão do Centro-Sul do país não pode e nem deve ser aplicado ao Norte-Nordeste, pois muitos são os desafios nestas regiões que necessitam ser superados, tais como a falta de cursos de qualidade em número suficiente, o problema da fixação de doutores com dedicação ao ensino, pesquisa e extensão, em especial, à pós-graduação e a dificuldade de fomentar uma política que possibilite a produção em forma de publicações qualificadas, atendendo aos critérios estabelecidos

\footnotetext{
${ }^{2}$ Osmar Fávero - Transcrição de depoimento em entrevista cedida às autoras em 2013.

3 Vera Maria Candau - Transcrição de depoimento em entrevista cedida às em 2012.

4 À época, Osmar Fávero era Professor pleno da FGV/IESAE.
} 
pela Capes (Qualis A e B Internacional) e, essencialmente, como meios de formação à sociedade brasileira.

Comungando dessas reflexões Marli André (2013), sobre políticas educacionais da pós-graduação stricto sensu e a necessidade de melhorias:

\begin{abstract}
Uma questão que ainda persiste na avaliação da Capes é a utilização de critérios homogêneos para todas as áreas. As áreas humanas têm aspectos próprios que não são contemplados nestes critérios comuns. [...] a formação humana do pós-graduando que tem peso considerável nas Humanas não tem sido valorizada na avaliação; A inserção social do curso na área das Humanas tem um peso considerável, enquanto que em outras áreas não. A avaliação com seus critérios homogêneos não contempla essas peculiaridades. Outra questão do modelo de avaliação da Capes é a atribuição de notas e rankings, baseadas nos critérios comuns. [...] As diferenças entre Novos e Consolidados também não é contemplada pelo modelo, ficando para os participantes das Comissões o encargo de modular essas diferenças. (Informação verbal) ${ }^{5}$.
\end{abstract}

A obra organizada por Rampinelli e Ouriques (2012), apresenta esclarecimentos acerca do termo "pesquisa", explicando que este tem sido denominado como "pesquisa" ou "produção científica" pelos órgãos responsáveis no Ministério da Ciência e Tecnologia e no Ministério da Educação. Na verdade, trata-se de um aumento vertiginoso da publicação dos docentes universitários brasileiros. Afirma-se que o simples estabelecimento de mestrados e doutorados não é garantia alguma de que a ciência esteja avançando no Brasil. Mencionam a existência de redes e mecanismos que os países metropolitanos organizam para captarem a inteligência dos países periféricos que são múltiplos e constantes, produto de uma política pensada e executada em seus mínimos detalhes.

Desse modo, o colonialismo assume feições tão destrutivas quanto trágicas na perspectiva intelectual. O elogio ao "acadêmico" no mundo universitário brasileiro tornou-se a maior expressão do colonialismo e representa a derrota acadêmica de toda pretensão intelectual. Quando à "[...] alienação tornar-se o melhor sinal da capacidade intelectual, é possível afirmar que o colonialismo atingiu seu grau máximo de domínio, na forma de política estatal, capaz de disciplinar a atividade do professor." (RAMPINELLI; OURIQUES, 2012, p. 91).

\footnotetext{
${ }^{5}$ Marli André - Transcrição de depoimento em entrevista cedida às autoras em 2013.
} 
Denunciam ainda que alguns, na gana de publicar, desafiam a imaginação na arte de copiar e/ou citar exaustivamente os cânones de moda na academia. E, precisamente por isso, o sistema mundial de produção de conhecimento necessita destes professores. Este trabalho é responsável por manter a atenção e o esforço do professor meritocrático sob controle impedindo-o de buscar as causas de sua alienação, de estabelecer vínculos com as grandes questões do mundo, da cultura e da ciência. Nesse cenário, artigos escritos com objetivos opostos ou repletos de inconsistências e de falta de lógica são aceitos e publicados, repetem-se ou participam da onda dominante.

Sendo assim, quando as autoridades educacionais indicam que temos um "sólido sistema de pós-graduação" funcionando, a dependência tecnológica cresce; as regras dos programas de pós-graduação seguem orientadas pelo colonialismo cultural e científico com acentuado rigor. Qual a explicação de revistas nacionais possuírem pontuação inferior às estrangeiras? Corroboram que, em muitas das publicações internacionais, os autores acabam fazendo parte de um sistema mundial de produção de conhecimento em que o/a professor/a figura como apenas mais um operário na linha de produção, embora se julgue muito distante do mundo fabril.

Nesta lógica da produtividade, a docência e a pesquisa passam a compor a universidade operacional produtiva e flexível. Chauí (2003) explicita que nesta, a docência é entendida como transmissão rápida de conhecimentos consignados em manuais de fácil leitura para os estudantes, de preferência, ricos em ilustrações e com duplicatas em CDs. O recrutamento de professores é feito sem levar em consideração o domínio de conhecimentos da disciplina e as relações entre elas e outras afins. $\mathrm{O}$ professor é contratado por ser um pesquisador promissor que se dedica a algo muito especializado, ou porque, não tendo vocação para a pesquisa, aceita contratos de trabalho temporários e precários, "flexíveis".

A formação de professores/as, a docência é pensada como habilitação rápida para os que precisam entrar rapidamente num mercado de trabalho do qual serão expulsos em poucos anos, pois, tornam-se jovens obsoletos, e descartáveis, ou, como correia de transmissão, e treino para novos pesquisadores. Transmissão e adestramento, desaparecendo a marca essencial da docência, a formação. 
Gonçalves Neto (1999) realçando palavras de Chauí (2003) discorre sobre o modelo de universidade operacional descrito pela autora nas políticas da pós-graduação stricto sensu brasileira:

\begin{abstract}
Desenha-se, portanto, um interesse contínuo dos setores produtivos da sociedade capitalista pelos trabalhos de pesquisa, de produção de inovações, que lhes permitam posicionar-se vantajosamente dentro do novo paradigma produtivo que se muda de forma vertiginosa, dependendo cada vez mais do progresso técnico e da criatividade dos trabalhadores etc. Por isso, o sistema educacional passa a ocupar posição privilegiada neste novo modelo de sociedade, já que os trabalhadores que irão ocupar os cargos no interior das empresas não podem seguir os velhos princípios assentados no taylorismo, mas precisam desenvolver habilidades específicas, capacidade de decisão etc., o que implica, no retorno da inteligência para o mundo da produção (GONÇALVES NETO, 1999, p. 231).
\end{abstract}

No que diz respeito à mudança no papel de atuação da Capes, Gatti, discorre sobre a necessidade de a formação envolver ensino e pesquisa de propostas alternativas a este modelo avaliativo da Capes, da má influência da burocracia, das diferenças substanciais entre o modelo de pós-graduação brasileiro e demais países, da subserviência da ciência brasileira, colonização do conhecimento, modelo de Estado neoliberal, o papel dos intelectuais, dentre outras:

A Capes começou a formalizar demais a avaliação dos cursos de pósgraduação, partindo pra uma quantificação que nós temíamos que esta quantificação ficasse assim, fosse levada a um limite até absurdo. Não chegou, mas está quase, né? Tudo é muito numerado. Você dá ponto para livros, ponto para isso, ponto para aquilo. Ninguém apresenta alternativa. Eu acho que isto é que tá faltando. Faltam alternativas que sejam apresentadas com força [...] É esse o momento que a gente vive. Nós chegamos ao limite do que eu chamo de uma numerologia [...] É o que eu digo a burocracia estatal. Ela tem um quê do autoritarismo, sim. E, por mais que se diga que seja discutido no Conselho, que é levado à sociedade, não é ouvido [...] uma ideinha do século XIX, que a ciência é una, que o modelo de ciência é único e, portanto, os critérios têm que ser universais [...] Então, tudo o que você procura, modelo único não é bom pra humanidade, não é bom para a humanidade, porque a humanidade é diversa. Então, e a Capes está nessa história de modelo único. Fica muito difícil. Nós somos muito subservientes a modelos externos numa universidade americana. Nós vivemos essa colonização do conhecimento, mas é pior que isso, porque a colonização do conhecimento pode ser boa na medida em que nosso colonizador detém um conhecimento muito importante, interessante. Mas é o outro lado, é a colonização sobre formas estruturais de produzir o conhecimento, é mais fundo, então, a colonização na forma de produzir o conhecimento, e isso é 
uma camisa de força [...] é o modelo de Estado que nós temos, gente! Nós temos que reconhecer que o governo que se instaurou, na proposta social, ele se tornou na área da educação uma proposta neoliberal, né? É o que nós estamos vivendo [...] o Luiz Carlos Freitas, por exemplo, que tem mostrado isso com muita clareza, né? Quer dizer, o modelo que está aí é o modelo de Estado Avaliador, é um modelo controlador. Nós perdemos a ideia de diagnóstico. Nas ciências humanas, nós precisamos de interlocução [...] Esta questão da Capes é complicada, e acho assim, que enquanto não mudar esta burocracia que se instalou ali. (Informação verbal ${ }^{6}$ ).

A educação produtivista encontra-se aliada à perda de autonomia nas universidades federais e nos programas de pós-graduação stricto sensu. O trabalho pedagógico pautado na pedagogia produtivista é caracterizado pela sua fragmentação e responde às demandas de disciplinamento do mundo do trabalho capitalista organizado e gerido segundo os princípios do taylorismo/fordismo, em três dimensões: técnica, política e comportamental. Nessas teorias, o papel conferido à disciplina copiada dos modelos das estruturas militares é um elemento básico na teoria clássica da administração. Este disciplinamento configura-se como uma transformação intelectual, cultural, política e ética, uma vez que tem por objetivo o desenvolvimento de uma concepção de mundo tão consensual quanto possível, tendo em vista as necessidades de valorização do capital.

A certificação da existência destes valores e princípios na política de pósgraduação brasileira é encontrada nas reflexões tecidas em diálogo estabelecido por Bordas e Silva (2011):

Bordas: [...] resgatar os ideais, os ideais dos ..., como diria, dos genuínos construtores da pós-graduação da área de educação, do sonho da área de educação com os valores e princípios que teriam que ter sido, então, isso tudo, minha cara, está colocado lá [...] Qual a evolução deste modelo, no sentido emancipador, libertador e em outro momento? Silva: Ou seja, que só reproduz, não emancipa. Bordas: É uma relação classificatória. Silva: E chama "qualis", se chama qualis e ser quantis, não tem nada de qualis. Só para o quantum ... Bordas: Aí o pessoal disse que, quantum? Peraí, eu tenho dez alunos, vou fazer cinquenta produções por ano, porque os dez alunos mandam pros outros lugares, os outros lugares colocarem outro nome... Quer cinquenta? Cinquenta. É uma ética perversa ... De promoção de uma práxis... De uma práxis, de uma anti-praxis emancipatória. Silva: [...] hoje a gente está numa lógica que é a hegemônica. Bordas: Senhores avaliadores, vocês não se sentem constrangidos, vocês não se sentem constrangidos por estarmos em

${ }^{6}$ B. Gatti . - Transcrição de depoimento em entrevista cedida às autoras em 2013. 
dois mil e onze, ter passado uma década, quase duas décadas, e estarmos na mesma mesmice, porra? Vocês não se sentem constrangidos de não ter conseguido aumentar os indicadores de avaliação de uma forma qualitativa? Vocês não têm vergonha? [...] depois de dez ou quinze anos o pessoal não tem vergonha e continua na mesma perversidade. O que pega não é apenas isso. $\mathrm{O}$ que pega é tanto tempo o pessoal deixa passar nas mãos, entrando mandato, saindo mandato e tendo coragem de andar com a cabeça levantada como se fossem os reis da avaliação, e a gente aguentando. Bordas: Isso é um modelo do Banco Mundial e do FMI. A imposição da USAID e educação [...] Da opressão ... Corpos oprimidos ... Corpos esmagados, corpos cerceados ... Silva: Docilização dos corpos... Corpo docente, corpo doente. Bordas: As tensões e as contradições. Silva: Não é uma política pra o desenvolvimento. Na verdade, é pra uma manutenção de uma ordem que já está estabelecida [...] A hierarquia, a manutenção da ordem, o poder de uma determinada ideologia. Bordas: Nós precisamos, à frente da pós-graduação, de pessoas capazes de lutar as nossas lutas. Não seria capaz de colocar alguém que não tivesse consciência histórica, entende? É muito mais do que militar. Não é apenas militar de farda. $\mathrm{O}$ mais perigoso é o hegemônico sem farda. Os de farda ainda tu vê qual é a cor e a farda. Tem os serviços que saem do comando da pró-reitoria, desses lugares que são militares sem farda. Que são bonecos ..., que são bonecos .... E que são bonecos robôs. É a robotização, a mecanização ... O pior é que estão travestidos. Estão travestidos de gente. Não estão mais vestidos de milicos. Estão à paisana, isso é o pior. Se ainda fossem fardados, você distinguia mais facilmente, mas estão travestidos de um discurso democrático [...] (Informação verbal) ${ }^{7}$.

As palavras de Bordas e Silva, como se pôde observar, inferem a implementação no âmbito da gestão educacional de princípios, métodos e formas de organização do trabalho desenvolvido em setores produtivos e de seus modelos de gerenciamento da produção que se dá por meio da incorporação de regras do mercado. A educação passa a ser concedida como serviço e não como um bem social.

\section{CONSIDERAÇÕES FINAIS}

Os escritos buscaram discutir sobre as políticas empreendidas pela Pósgraduação em Educação em seu percurso histórico, a exemplo do sistema de avaliação desenvolvido pela Capes, sendo possível confirmar a tese de que os direcionamentos da agência de política de avaliação e financiamento não estão sendo defendidos e definidos em princípios pautados numa formação emancipatória, uma vez que, dos textos analisados, não encontramos escritos que denotem emancipação política e humana, pois

\footnotetext{
${ }^{7}$ Bordas e Silva - Transcrição de depoimento em entrevista cedida às autoras em 2013.
} 
estão presos aos ditames desta política de Estado há mais de sessenta anos. Isso configura-se numa submissão e alienação da comunidade acadêmica às orientações ditadas pela Capes em detrimento de possibilidades de emancipação e autonomia.

Constata-se, ainda, a permanência de assimetrias regionais para as regiões Norte, Nordeste e Centro-Oeste, as quais não têm trazido mudanças significativas como já as materializadas nas regiões Sul e Sudeste. Programas com conceitos de 5 a 7 , número fixo de doutores/as, número exíguo de bolsas de pesquisa, apoio à infraestrutura, revistas e periódicos com Qualis A, dentre outras diferenças que persistem, sendo que as políticas desenvolvidas pela Capes mantêm.

Em seu percurso histórico, os direcionamentos da Capes ficaram atrelados às reconfigurações socioeconômicas, políticas e culturais do capitalismo e às alterações no papel do Estado brasileiro.

Esta análise/afirmação pode ser percebida numa preocupação exacerbada ao cumprimento de normas e critérios existentes no quesito publicação com acentuado prestígio de periódicos internacionais em detrimento dos nacionais. Os critérios de avaliação Capes e a lógica de produtividade na Pós-graduação estão expressas na orientação de que os periódicos com notas maiores são aqueles publicados em língua inglesa. Cabe indagar: de que produção se fala ou se silencia e, para quem?

As vozes dos sujeitos e dos documentos da Capes para a Pós-graduação na área de Ciências Humanas e Educação possibilitou-nos estabelecer a relação entre o que realmente está dito nos e pelos planos de pós-graduação e o que tem sido concretizado no interior das políticas educacionais para este nível.

Em prol da existência de um sujeito histórico, o diálogo necessita se fazer presente cotidianamente entre os que compõem o processo educacional da Pósgraduação e aqueles/as que elaboram e definem os princípios para regê-la nacional e internacionalmente. Daí a necessidade de continuarmos defendendo a Educação como construção e reconstrução de culturas de resistência. Sendo imprescindível a participação dos sujeitos nela envolvidos, em fóruns de debates e em movimentos de classes que oportunizem a reflexão sobre o conhecimento e sua relevância social para a formação humana, como sujeitos e não como objetos reprodutores de uma lógica 
alienante. Que se dê continuidade ao processo de superação da lógica perversa e desumana de formação na Pós-graduação brasileira no tempo presente.

Urge modificar as políticas educacionais da Pós-graduação stricto sensu desenvolvidas pela Capes, assim como o compromisso dos professores e pesquisadores envolvidos nos programas de Pós-graduação em Educação que, como intelectuais, podem mediar outras lógicas, outras culturas diferentes das pautadas na lógica do poder, da competitividade, da docilização e da regulação; de conhecimentos e culturas ancoradas no pilar da emancipação de uma educação como construção e reconstrução de culturas de resistência ao projeto de sociedade neoliberal. Enfim, é necessário que nos conscientizemos de lutar por uma educação emancipatória e não aceitarmos esta educação produtivista que tem sido defendida e definida em nosso país.

\section{REFERÊNCIAS}

BIANCHETTI, Lucídio. Os dilemas do coordenador de programa de pós-graduação: entre o burocrático-administrativo e o acadêmico-pedagógico. In: SGUISSARDI, Valdemar; BIANCHETTI, Lucídio. (Org.). Dilemas da pós-graduação, gestão e avaliação. Campinas: Autores Associados, 2009. p. 16-99 (Coleção educação contemporânea).

BOTTOMORE, Tom. Dicionário do pensamento marxista. 2. ed. Rio de Janeiro: Zahar, 2012.

BRASIL. Ministério da Cultura. Capes 60 anos - seis décadas de evolução da pósgraduação. Revista Comemorativa, Brasília: [s.n.], jul. 2011.

Ministério da Educação. Estatísticas da Pós-graduação. Brasília: Capes. Disponível em: <http://www.capes.gov.br/sobre/estatisticas/> Acesso em: 06 ago. 2007.

Ministério da Educação. Plano Nacional de Pós-graduação (PNPG 20112020). Brasília: Capes. Disponível em: < http:// www.capes.gov.br/sobre-a-capes/planonacional-de-pos-graduacao/pnpg-2011-2020>. Acesso em: 12 jan.2014.

Coordenação de Aperfeiçoamento de Pessoal do Nível Superior - CAPES.

História e missão da CAPES. Brasília (DF). Disponível em: <http://www.capes.gov.br/sobre-a-capes/historia-e-missao> Acesso em: 30 jul. 2010.

Avaliação da pós-graduação. Brasília (DF). Disponível em: <http://www.capes.gov.br/ avaliacao/avaliacao-da-pos-graduacao>. Acessado em: 07 jun. 2010.

Critérios de avaliação trienal (2004-2006). Brasília (DF), 2007. Disponível 
em:

<http://www.capes.gov.br/images/stories/download/avaliacao/CA2007

Educacao.pdf $>$. Acesso em: 07 jun. 2010.

CASTRO, C. M. Há produção científica no Brasil? Ciência e Cultura. São Paulo, v. 37, p. 165-87, 1985. (Suplemento 7)

CHAUÍ, Marilena de Souza. A universidade pública sob nova perspectiva. Revista Brasileira de Educação, [S.1.], n. 24, set./dez. 2003. Disponível em: 〈http://www.scielo.br/pdf/rbedu/n24/n24a02.pdf〉. Acesso em: 09 ago. 2010.

CURY, Carlos Roberto Jamil. Da crítica à avaliação à avaliação crítica. In: SGUISSARDI, Valdemar; BIANCHETTI, Lucídio. (Org.). Dilemas da pósgraduação, gestão e avaliação. Campinas: Autores Associados, 2009. Prefácio. (Coleção Educação Contemporânea).

FÁVERO, Osmar. Reavaliando as avaliações da Capes - Programa de PósGraduação em Educação. [Rio de Janeito]: Universidade Federal Fluminense, 1998. Disponível em: 〈http://www. anped.org.br/aval1.doc〉. Acesso em: 11 set. 2011.

FERREIRA, Marieta de Moraes; MOREIRA, Regina da Luz (Org.). CAPES 50 anos: depoimentos ao CPDOC/ FGV. Brasília: CAPES, 2002. Disponível em: <http://www.capes.gov.br>. Acesso em: 02 agosto 2007.

GATTI, B.; ANDRÉ, M.; FÁVERO, O.; CANDAU, V. M. F. O modelo de avaliação da Capes. Revista Brasileira de Educação, Rio de Janeiro, n. 22, , 2003. Disponível em: http://www.scielo.br/scielo.php?script=sci_arttext\&pid=S1413-24782003000100012>.

Acesso em: 11 set. 2011.

GONÇALVES NETO, Wenceslau. Rumos da pós-graduação brasileira: geração de conhecimento, formação de pessoal e abertura de novos cursos. Educação e Filosofia, Uberlândia, v. 13, n. 25, p. 231-248, jan. 1999.

HORTA, José Silvério Baia. Avaliação da pós-graduação: com a palavra os coordenadores de programas. In: SGUISSARDI, Valdemar; BIANCHETTI, Lucídio. (Org.). Dilemas da pós-graduação, gestão e avaliação. Campinas: Autores Associados, 2009. p. 102-131. (Coleção Educação Contemporânea)

REVISTA BRASILEIRA DE EDUCAÇÃO. V Plano Nacional de Pós-Graduação: subsídios apresentados pela ANPEd. Rev. Bras. Educ. no. 27, Rio de Janeiro Sept./Oct./Nov./Dec. 2004. Disponível em: <http://dx.doi.org/10.1590/S141324782004000300015> Acesso em: 10 de agosto de 2017

RAMPINELLI, Waldir José; OURIQUES, Nildo. Crítica à razão acadêmica. In: OURIQUES, Nildo. (Org.). Ciência e pós-graduação na Universidade Brasileira. 2. ed. Florianópolis: Insular, 2012. p. 73-107.

SILVA, Maria Cecília de Paula. Do corpo objeto ao sujeito histórico - perspectivas do corpo na história da educação brasileira. Salvador: EDUFBA, 2009. 